\title{
Hypertension Management in Primary Care
}

\author{
A Cluster Randomized Trial of a Physician-focused Educational Intervention
}

\author{
Birgitta Weltermann, Christine Kersting, Anja Viehmann
}

\section{SUMMARY}

Background: To improve hypertension control, this cluster randomized trial evaluated the effectiveness of physician manager education about hypertension management.

Methods: After randomization at practice level, primary care physicians of the intervention arm, whose practices collaborated with a university department, participated in a three-session education on evidence-based hypertensiology and practice implementation strategies. The primary outcome was blood pressure (BP) control (ambulatory blood pressure $[A B P]<130 / 80 \mathrm{mmHg}$ ) after 5 months. Secondary outcomes were changes in BP and practice routines regarding hypertension management. Following an intention-to-treat approach, data analyses included crude and adjusted generalized mixed models and sensitivity analyses. These took into account sex, age, $\geq$ hypertension-related disease and resistant hypertension (RH).

Results: The analysis included 103 of 169 patients from 22 practices. Overall, BP decrease was -8.2 systolic and $-4.1 \mathrm{mmHg}$ diastolic. The intervention had no effect on BP control (odds ratio 0.84 [95\% $\mathrm{Cl} 0.29-2.43]$ ) and BP changes (interventional effect: systolic $-2.48 \mathrm{mmHg}$ [95\% Cl -7.24 to 2.29], diastolic $-0.25 \mathrm{mmHg}$ [95\% Cl 3.31 to 2.82]). Sensitivity analysis indicated effect modification in patients with $\mathrm{RH}$. Intervention practices requested educational input on difficult cases, and newly implemented 3 practice strategies $(14.5 \pm 2.6$ versus $11.4 \pm 2.2 ; P=0.005)$.

Conclusions: After the short follow-up of 5 months, the intervention had no impact on BP control but improved the use of practice strategies.

\section{- Cite this as:}

Weltermann B, Kersting C, Viehmann A: Hypertension management in primary care-a cluster randomized trial of a physician-focused educational intervention. Dtsch Arztebl Int 2016; 113: 167-74.

DOI: 10.3238/arztebl.2016.0167
T he need to improve blood pressure (BP) control is documented in various studies $(1,2)$. Targeting patients, health care professionals and organizations, randomized controlled trials and cluster randomized trials (CRTs) have evaluated various interventions to improve BP control. Examples are :

- patient-centered approaches (e.g. electronic reminders for self-care [3])

- clinical pharmacist-led patient programs $(4,5)$

- physician-centered strategies (including: provider-specific benchmarking reports [6], therapeutic recommendations by an external data center (7), physician-pharmacist collaborations [8-10])

- separate hypertension outpatient clinics (11).

Although epidemiological data documented outcome improvements with reduced cardiovascular events even after reductions of $-2 \mathrm{mmHg}$ systolic BP (12), this is difficult to implement in routine care. The health services interventions mentioned above showed heterogeneous interventional effects on systolic BP (SBP) $(+0.18$ to $-10.2 \mathrm{mmHg}[5,10])$ and diastolic BP (DBP) $(+0.04$ to $-4.6 \mathrm{mmHg}[6,9])$ (Figure 1). According to a Cochrane review, best effects were achieved when educational and organizational approaches were combined (13), with a five-year follow-up demonstrating a significant decrease in mortality (11)

While the majority of these interventions used rather costly external support structures, few randomized studies combined internal practice redesign with educational strategies $(14,15)$ : Reuther et al. (2012) combined physician education about clinical management and practice organization with a clinical decision support system, benchmarking, peer audits, and a specialist hotline: After a 24-month follow-up in 2646 patients from 124 practices, the interventional effects amounted to $-1.75 \mathrm{mmHg}$ systolic [95\% confidence interval (CI) 4.02 to 0.53 ] and $+0.14 \mathrm{mmHg}$ diastolic [95\% CI: -1.16 to 1.44 ] (15).

We studied whether a series of three continuing medical education (CME) sessions for primary care physicians on evidence-based hypertensiology and practice redesign changed BP control rate and practice strategies. Our CRT addressed physicians in their dual role as clinicians and managers (so called "physician managers") which is appropriate for the German health care system 


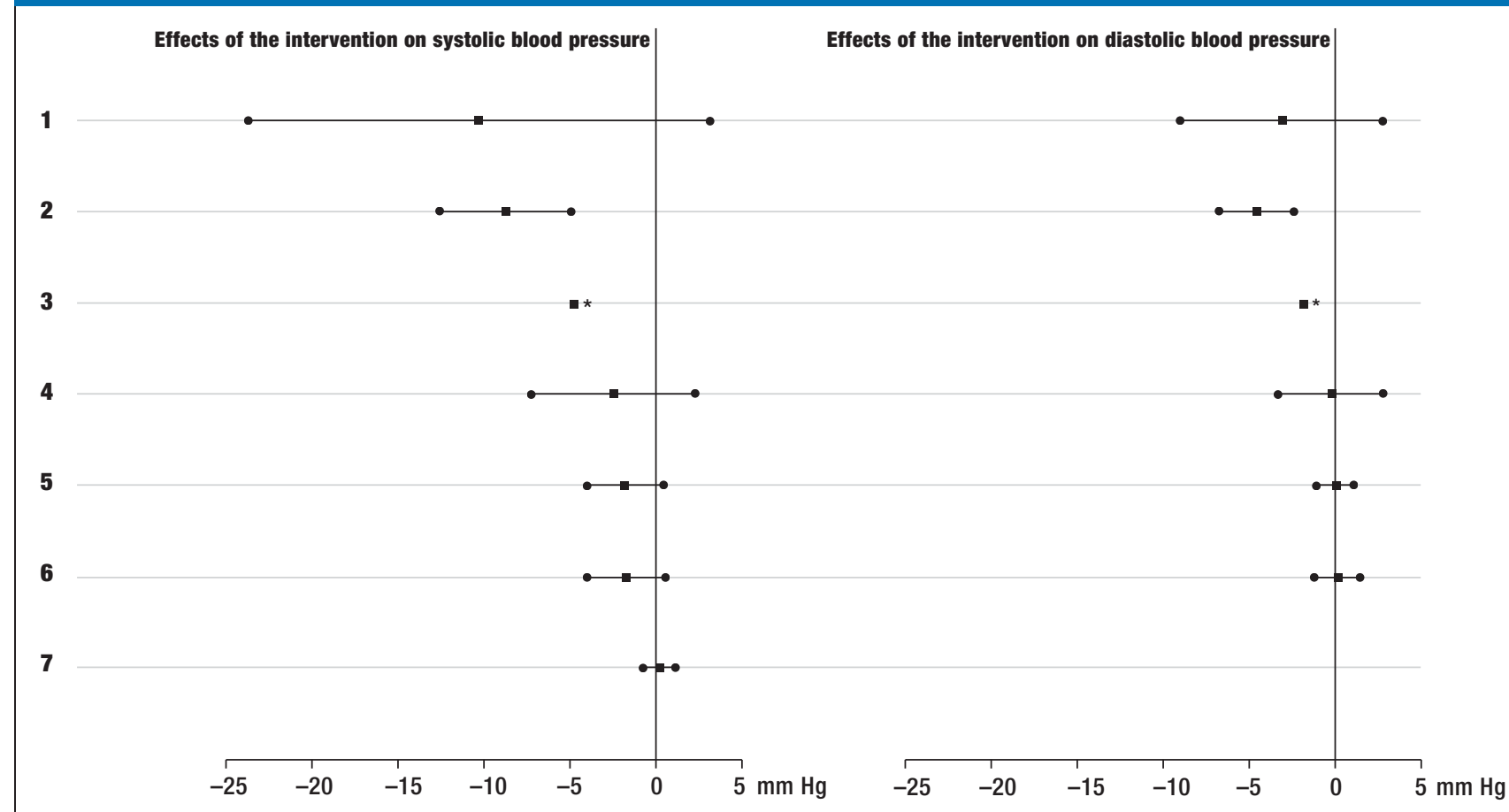

1 Physician education, written patient information, physician/pharmacist collaboration (5 US clinics, 179 patients, ABPM, 9 months follow-up) (9)

2 Physician education, written patient information, physician/pharmacist collaboration (6 US clinics, 402 patients, ABPM, 6 months follow-up) (10)

3 Physician education, introduction of ABPM into practice, feedback on clinical data (23 French primary care physician clusters with 335 physicians, 1832 patients, office BP, 24 months follow-up) (14)

4 Our study: Tailored physician education, strategies to facilitate practice implementation (22 German primary care practices, 103 patients, ABPM, 5 months follow-up)

5 Physician education, written patient information, audit reports for practice, benchmarking (93 US providers [60\% primary care physicians], 7159 patients, office BP, 6 months follow-up) (6)

6 Physician educatiog, feedback on practice patterns regarding hypertension, benchmarking, specialist hotline, clinical decision support system for medication (124 Danish primary care practices, 2646 patients, office BP, 24 months follow-up) (15)

7 Clinical pharmacist-led patient program, medication changes based on algorithm (5 US outpatient centers, 4100 patients, office BP [systolic only], 6 months follow-up) (5)

Cluster randomized trials about interventions to improve hypertension therapy: effects on systolic and diastolic blood pressure (in mmHg). Reference: control group.

${ }^{*} 95 \% \mathrm{Cl}$ not reported..

US, United States; ABPM, ambulatory blood pressure monitoring; BP, blood pressure

where the majority of practices are physician-owned. BP was measured using the gold standard ambulatory blood pressure monitoring (ABPM).

\section{Methods}

\section{Study design}

This CRT involved practices from the general medicine practice network of the University of Duisburg-Essen, Germany. The cluster design was used because the intervention addressed the physician/practice level, while it aimed at improving patients BP indirectly (16). At the 2013 spring network meeting all 51 attending practices were invited to participate.

Practices were eligible if they cared for hypertensive patients and were equipped with a calibrated
ABPM device. In September 2013, 24 practices that volunteered and met the inclusion criteria were randomly assigned to the intervention or control arm (1:1) (17). To blind physicians for their interventional status, participants of the control arm received the same intervention after follow-up (waiting list control).

Allocation of patients was conducted at cluster level. All participants provided informed consent. The follow-up data collection was completed in August 2014. The Ethics Commission of the Medical Faculty of the University of Duisburg-Essen issued a positive vote for the study (reference: 13-5537-BO, date: 09/09/2013). Details of the study design are published elsewhere (17). 


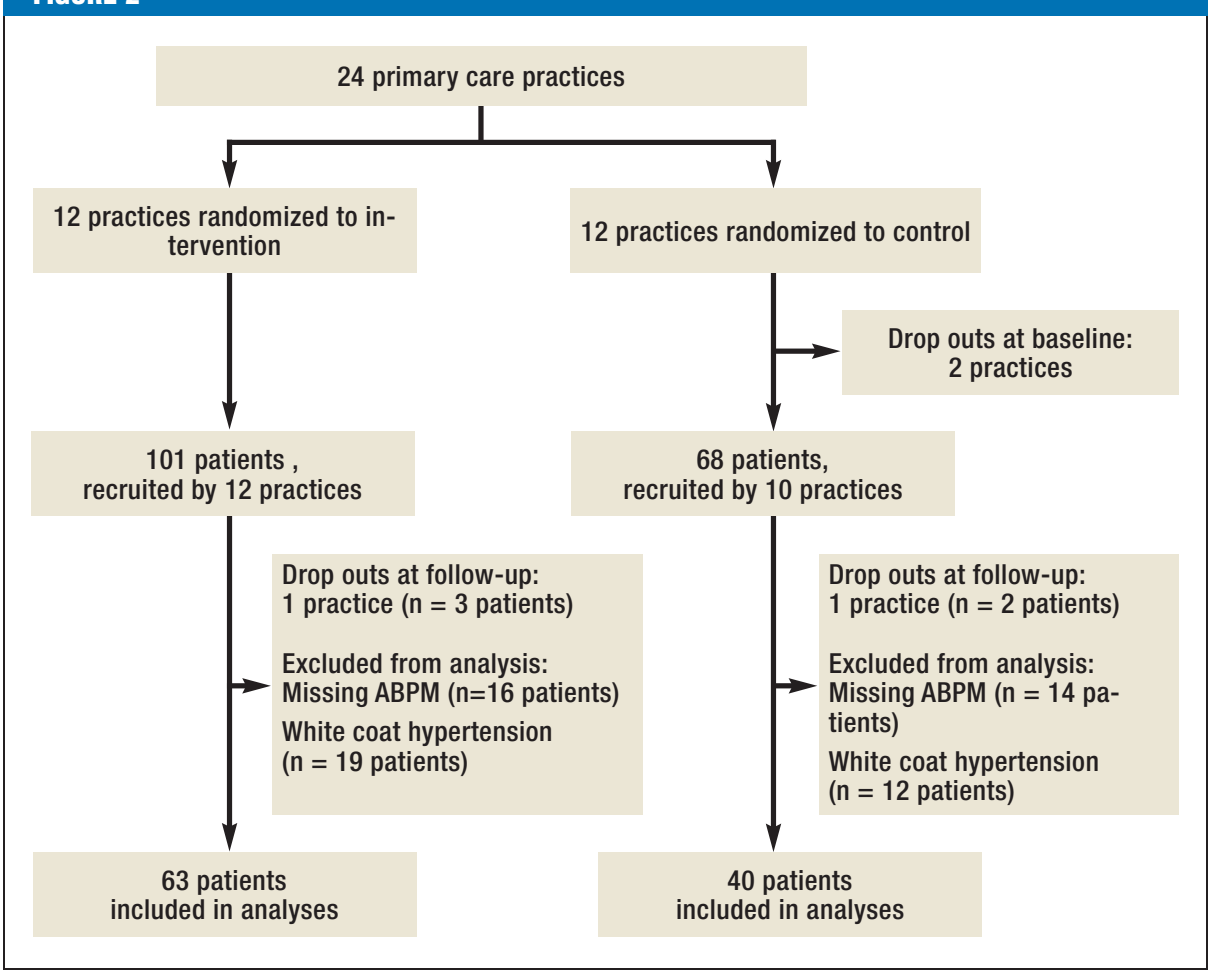

\section{Study participants}

The practices were asked to recruit at least 10 consecutive hypertensive patients with or without prior medication and/or hypertension-related diseases fulfilling the inclusion criteria:

- Age $\geq 18$ years

- ability to complete the study documents

- uncontrolled BP according to the European hypertension guidelines: office BP readings of $\geq 140 / 90 \mathrm{~mm} \mathrm{Hg}$, ABP readings of $\geq 130 / 80 \mathrm{~mm} \mathrm{Hg}$ or mean home measurements of $\geq 135 / 85 \mathrm{~mm} \mathrm{Hg}$ in a one-week protocol with $\geq 2$ measurements daily (18)

Because patients were recruited for the study prior to their ABPM, patients with white coat hypertension (ABP $<130 / 80 \mathrm{mmHg}$ ) were excluded from the final analysis.

\section{Intervention}

Practices received a physician manager-focused intervention offering strategies for structured hypertension management (17). Aiming at a participatory approach, physicians were asked for their information needs. Three CME sessions combined evidence-based information and practice implementation strategies:

- Presentation of BP devices and training on valid $\mathrm{BP}$ readings

- information about diagnostic and therapeutic strategies including pharmacotherapy

- approaches for managing patients with white coat, secondary, juvenile and resistant hypertension ( $\mathrm{RH})$
- implementation of tools to facilitate guideline adherence

The sessions were provided by four hypertension specialists with one being experienced in practice hypertension management. Physicians were free to choose the diagnostic and therapeutic regimens for their patients.

\section{Outcomes}

The primary outcome was the BP control rate (percentage of patients with an average ABP $<130 / 80 \mathrm{mmHg}$ [18]) in the intervention and the control arm after five months. Secondary outcomes were :

- changes in systolic and diastolic ABP (in mmHg), and

- changes in practice strategies.

$\mathrm{ABP}$ was measured at baseline and 5 months followup.

For covariate assessment, study patients completed a questionnaire on sociodemographic characteristics, lifestyle factors, adherence, and BP self-checks at baseline and follow-up. At both times, physicians provided the patients' medical characteristics including information on antihypertensive medication (substances, dosages, daily distribution) and practice strategies used. Practice and physician characteristics (sex, age, qualifications) were obtained at baseline.

\section{Statistical methods}

Based on our pilot study, BP control rates of 35\% for the control and $70 \%$ for the intervention group were 
TABLE 1

Baseline characteristics of participating patients

\begin{tabular}{|c|c|c|c|}
\hline Study patient & $\begin{array}{l}\text { Intervention } \\
\quad(n=63)\end{array}$ & $\begin{array}{l}\text { Control } \\
(n=40)\end{array}$ & $p^{*}$ \\
\hline Age, years, mean \pm SD & $58.7 \pm 13.5$ & $63.4 \pm 13.4$ & 0.111 \\
\hline Male, n (\%) & $34(54.0)$ & $24(60.0)$ & 0.548 \\
\hline Married, n (\%) & $40(64.5)$ & $25(62.5)$ & 0.836 \\
\hline Employed, n (\%) & $30(48.4)$ & $16(40.0)$ & 0.406 \\
\hline$\geq 1$ burden in daily life, $n(\%)$ & $37(59.7)$ & $25(62.5)$ & 0.776 \\
\hline - Stress at work, n (\%) & $27(43.5)$ & $8(20.0)$ & 0.014 \\
\hline - Concerns about family issues, $\mathrm{n}(\%)$ & $10(16.1)$ & $10(25.0)$ & 0.271 \\
\hline - Physically strenuous work, $n$ (\%) & $13(21,0)$ & $5(12.5)$ & 0.273 \\
\hline - Overtime at work, n (\%) & $8(12.9)$ & $6(15.0)$ & 0.764 \\
\hline - Noise, dust, gases, fumes, n (\%) & $10(16.1)$ & $4(10.0)$ & 0.380 \\
\hline - Concerns about job security, n (\%) & $6(9.7)$ & $5(12.5)$ & 0.748 \\
\hline - Rotating shifts/night shift, n (\%) & $8(12.9)$ & $3(7.5)$ & 0.521 \\
\hline Poor subjective health status, $n$ (\%) & $25(40.3)$ & $20(50.0)$ & 0.337 \\
\hline $\mathrm{BMI}, \mathrm{kg} / \mathrm{m}^{2}$, mean $\pm \mathrm{SD}$ & $30.9 \pm 6.0$ & $30.8 \pm 6.6$ & 0.986 \\
\hline Regular physical activity, n (\%) & $28(45.9)$ & $14(35.9)$ & 0.323 \\
\hline Smoker, n (\%) & $17(27.9)$ & $5(12.8)$ & 0.076 \\
\hline $\begin{array}{l}\text { Years since first hypertension diagnosis, } \\
\text { mean } \pm \text { SD }\end{array}$ & $8.6 \pm 8.3$ & $9.5 \pm 8.8$ & 0.612 \\
\hline Regular BP self-checks, $n$ (\%) & $37(62.7)$ & $25(62.5)$ & 0.983 \\
\hline Receives antihypertensive(s), $\mathrm{n}(\%)$ & $61(96.8)$ & $37(92.5)$ & 0.374 \\
\hline $\begin{array}{l}\text { Number of antihypertensive agents, } \\
\text { mean } \pm \text { SD }\end{array}$ & $2.7 \pm 1.7$ & $2.8 \pm 1.6$ & 0.858 \\
\hline Resistant hypertension, n (\%) & $28(44.4)$ & $24(60.0)$ & 0.124 \\
\hline $\begin{array}{l}\text { Diagnosis of } \geq 1 \text { hypertension-related } \\
\text { secondary disease and/or diabetes mellitus } \\
\text { type } 2, n(\%)\end{array}$ & $34(54.0)$ & $24(60.0)$ & 0.548 \\
\hline - Diabetes mellitus type 2, n (\%) & $23(37.1)$ & $17(45.9)$ & 0.385 \\
\hline - Coronary heart disease, $\mathrm{n}(\%)$ & $8(12.7)$ & $8(20.0)$ & 0.319 \\
\hline - Chronic renal insufficiency, n (\%) & $6(9.8)$ & $6(16.2)$ & 0.361 \\
\hline - Cardiac insufficiency, n (\%) & $4(6.5)$ & $5(12.8)$ & 0.302 \\
\hline - Stroke, n (\%) & $6(9.7)$ & $2(5.1)$ & 0.480 \\
\hline Mental disorder, $\mathrm{n}(\%)$ & $18(28.6)$ & $8(21.1)$ & 0.402 \\
\hline Secondary hypertension, $\mathrm{n}(\%)$ & $7(11.3)$ & $5(13.5)$ & 0.758 \\
\hline
\end{tabular}

Percentages are reported for valid cases.

$\mathrm{SD}$, standard deviation; BMI, body mass index; BP, blood pressure

* Data of the intervention and the control arm were compared using chi-square tests for categorical variables and t-tests in independent samples for continuous variables

considered for sample size calculation (19, 20). Assuming an equal number of clusters per study arm, an average cluster size of 5 patients and an intraclass correlation coefficient of 0.05 (16), 10 clusters per study arm were required to detect the expected proportions with a two-sided significance level of 0.05 (80\% power). The sample size was calculated with R Package 'CRTSize', function n4props (21, 22).
Following an intention-to-treat approach (23) the analysis included all study patients with an ABPM at baseline and follow-up expect those with white coat hypertension (ABPM readings $<130 / 80 \mathrm{mmHg}$ at baseline (18)). The chi-square test was used to compare BP control rates between intervention and control. Using generalized linear mixed models (GLM), crude and adjusted analyses were performed to determine the effect of the intervention on BP control with the control arm as reference. The models accounted for clustered data by random effect modeling with an unstructured covariance pattern. The effect of the intervention on BP control is described as an odds ratio (OR) with 95\% confidence interval.

GLMs were also calculated for BP changes (secondary outcomes). The interventional effects on SBP and DBP were expressed as point estimates. The GLMs for the total analysis population were adjusted for sex, age, and having $\geq 1$ hypertension-related disease as a marker for disease severity. To assess effect modification, stratified sensitivity analyses were performed for sex, age ( $\leq 61,>61)$, having $\geq 1$ hypertension-related disease and the presence of $\mathrm{RH}$ ( $\geq 3$ antihypertensive substances). The latter was a post-hoc analysis triggered by the learning content requested by the participants. Additionally, GLMs were calculated for the extended study population including patients with white coat hypertension.

Statistical analyses were performed with IBM SPSS Statistics, Version 22.0; GLMs were calculated with SAS, Version 9.4. Statistical significance was set at $\mathrm{p}<0.05$. There was no correction for multiple testing.

\section{Results \\ Practice and physician characteristics}

24 of the 51 invited practices volunteered and met the inclusion criteria (47.1\%). They were randomly assigned to the intervention $(\mathrm{n}=12)$ or the waiting list control arm $(\mathrm{n}=12)$ and recruited 169 patients: intervention arm, $n=101$, control arm, $n=68$ (Figure 2). Four practices dropped out during data collection (1 physician died, 3 practices discontinued due to lack of interest). In key characteristics, these did not differ from participating ones. Also, physicians from both study arms were comparable (Table 1, eTable 1).

Physicians of the intervention arm requested the following input:

- Management of difficult cases (42.9\%, n=6 of 14 requests) and/or complex medication regimens (28.6\%, $n=4)$;

- Standardized BP measurements including reliability and validity of new devices $(21.4 \%, n=3)$;

- Motivational strategies to assure patients' adherence $(7.1 \%, n=1)$.

\section{Patient characteristics}

ABPM documentation at baseline and follow-up was available for 134 patients (79.3\%). Excluding 31 patients (23.1\%) with white coat hypertension, the final analysis included 103 patients: intervention arm, $n=63$; 
control arm, n=40. Characteristics of patients excluded were similar to those included. Of the 7.7 patients (range 1-11) per practice initially recruited, 5.2 patients (range 1-8) were included in the final analysis.

Patient baseline characteristics were similar in both groups, except for more work-related stress in the intervention arm (43.5\% ( $\mathrm{n}=27)$ versus $20.0 \% \quad(\mathrm{n}=8)$, $P=0.014$ ) (Table 1, eTable 1).

On average, patients with $\mathrm{RH}(\mathrm{n}=52)$ were older $(P=0.001)$, were taking more antihypertensives $(P<0.001)$, had a longer history of hypertension $(P<0.001)$, and a higher prevalence of coronary heart disease $(P<0.001)$ than those without RH (Table 2).

\section{Blood pressure}

The intervention had no effect on BP control or BP changes. However, after five months, ABP was controlled in $19.4 \%$ of the patients (20 of 103 patients), without a difference between study arms (intervention: $\mathrm{n}=12,19 \%$; control: $\mathrm{n}=8,20 \% ; P=0.905$ ) (Table 3, eTable 2). The crude OR for the intervention's effect on BP control was 0.94 (95\% CI: [0.34; 2.58]), the adjusted OR was 0.84 [0.29; 2.43].

Mean ABP was $147 / 85$ mmHg $( \pm 12.1$ systolic/ \pm 9.1 diastolic) initially and decreased to $139 / 81 \mathrm{mmHg}$ $( \pm 13.1 / \pm 10.0)$ at follow-up without differences between study arms (Table 3, eTable 2). BP decreased by $9.3 / 4.2 \mathrm{mmHg}( \pm 11.9 / \pm 7.9)$ in the intervention and by $6.7 / 3.8 \mathrm{mmHg}( \pm 11.7 / \pm 6.9)$ in the control arm. The intervention had no effect on the change in BP: SBP $-2.55 \mathrm{mmHg}[-7.28 ; 2.19]$ in the crude model, -2.48 mmHg SBP [-7.24; 2.29] in the adjusted model, and likewise DBP $-0.28 \mathrm{mmHg}[-3.29 ; 2.73]$ and -0.25 mm Hg [-3.31; 2.82]) (eFigure $b, c)$. Inclusion of patients with white coat hypertension barely changed these estimates (eFigure $a, b, c$ ).

The post-hoc sensitivity analysis indicated some effect modification for SBP when stratifying by RH: The adjusted SBP change was $-6.75 \mathrm{mmHg}[-13.36$; -0.13 ] (eFigure $b$ ). There was no indication for effect modification when stratifying for sex, age, and having $\geq 1$ hypertension-related disease (eFigure $a, b, c$ ).

\section{Changes in practice management and medication}

At baseline, intervention and control practices used a similar number of hypertension management strategies (11.0 \pm 2.8 versus $10.8 \pm 1.5, P=0.859$ ), which increased by three strategies in intervention practices $(14.5 \pm 2.6$ versus 11.4 $\pm 2.2, P=0.005)$. At the patient level, the following practice strategies were newly applied in the intervention group: supervision of BP self-checks (82.3\%, $n=51)$, diagnostics for renal disease $(77.4 \%, n=48)$, prescription of a BP monitor $(41.9 \%, n=26)$, optimized psychiatric treatment $(15.9 \%, n=10)$. Intervention patients received more follow-up appointments than control patients (7.0 \pm 9.7

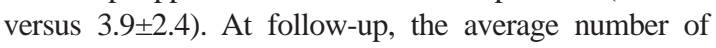
antihypertensives equaled between the study arms (both 3.2 , intervention \pm 1.6 , control \pm 1.3 ), only $\mathrm{RH}$ patients of the intervention arm were taking 0.5 agents more (4.5 \pm 1.2 versus $4.0 \pm 1.0, \mathrm{P}=0.072$ ) (Table 2).

\section{TABLE 2}

Characteristics of patients with resistant hypertension

\begin{tabular}{|c|c|c|c|}
\hline Baseline characteristics & $\begin{array}{l}\text { Intervention } \\
\quad(n=28)\end{array}$ & $\begin{array}{l}\text { Control } \\
(n=24)\end{array}$ & $\mathrm{p}^{* 1}$ \\
\hline Age, years, mean \pm SD & $63.6 \pm 16.7$ & $66.9 \pm 11.3$ & 0.421 \\
\hline Male, $n(\%)$ & $18(64.3)$ & $15(62.5)$ & 0.894 \\
\hline Poor subjective health status, $\mathrm{n}(\%)$ & $14(50.0)$ & $15(62.5)$ & 0.366 \\
\hline Overweight, n (\%) & $21(84.0)$ & $19(90.5)$ & 0.673 \\
\hline Regular physical activity, $\mathrm{n}(\%)$ & $15(53.6)$ & $10(41.7)$ & 0.392 \\
\hline Smoker, n (\%) & $8(29.6)$ & $2(8.3)$ & 0.168 \\
\hline $\begin{array}{l}\text { Years since first diagnosis of hypertension, } \\
\text { mean } \pm \text { SD }\end{array}$ & $14.1 \pm 8.4$ & $12.1 \pm 7.6$ & 0.414 \\
\hline Regular BP self-checks, $n(\%)$ & $20(74.1)$ & $17(70.8)$ & 0.796 \\
\hline $\begin{array}{l}\text { Diagnosis of } \geq 1 \text { hypertension-related } \\
\text { secondary disease and/or diabetes mellitus } \\
\text { type } 2, n(\%)\end{array}$ & $18(64.3)$ & $18(75.0)$ & 0.404 \\
\hline $\begin{array}{l}\text { Follow-up: Changes in patients' hyper- } \\
\text { tension management }\end{array}$ & $\begin{array}{l}\text { Intervention } \\
(\mathrm{n}=28)\end{array}$ & $\begin{array}{l}\text { Control } \\
(n=24)\end{array}$ & $\mathrm{p}^{*^{1}}$ \\
\hline $\begin{array}{l}\text { Examination of the upper-arm cuff of pa- } \\
\text { tients' BP monitor, } n(\%)\end{array}$ & $23(82.1)$ & $9(37.5)$ & 0.001 \\
\hline Prescription for BP monitor, n (\%) & $13(46.4)$ & $2(8.3)$ & 0.003 \\
\hline Optimization of psychiatric treatment, $n(\%)$ & $7(25.0)$ & $0(0)$ & 0.011 \\
\hline Supervision of BP self-checks, $n(\%)$ & $24(85.7)$ & $14(58.3)$ & 0.026 \\
\hline $\begin{array}{l}\text { Mean number of follow-up appointments per } \\
\text { patient, mean } \pm \text { SD }\end{array}$ & $5,4 \pm 2,5$ & $4,6 \pm 2,4$ & 0,275 \\
\hline Referral to a hypertensiology center, $\mathrm{n}(\%)$ & $3(11,1)$ & $1(4,2)$ & 0,612 \\
\hline $\begin{array}{l}\text { Evaluation for secondary hypertension } \\
\text { (renal insufficiency, pheochromocytoma, } \\
\text { Conn syndrome, sleep apnea), n (\%) }\end{array}$ & $21(77.8)$ & $19(79.2)$ & 0.904 \\
\hline Medication & $\begin{array}{l}\text { Intervention } \\
\quad(n=28)\end{array}$ & $\begin{array}{l}\text { Control } \\
(n=24)\end{array}$ & $\mathrm{p}^{*^{1}}$ \\
\hline $\begin{array}{l}\text { Number of antihypertensive agents at base- } \\
\text { line, mean } \pm S D\end{array}$ & $4.2 \pm 1.2$ & $3.8 \pm 1.0$ & 0.225 \\
\hline $\begin{array}{l}\text { Number of antihypertensive agents at } \\
\text { follow-up, mean } \pm \text { SD }\end{array}$ & $4.5 \pm 1.2$ & $4.0 \pm 1.0$ & 0.072 \\
\hline $\begin{array}{l}\text { Change in antihypertensive agents, mean } \pm \\
\text { SD }\end{array}$ & $+0.3 \pm 0.8$ & $+0.2 \pm 0.3$ & 0.231 \\
\hline $\mathrm{p}^{*^{2}}$ & 0.036 & 0.083 & \\
\hline
\end{tabular}

Percentages are reported for valid cases.

$\mathrm{SD}$, standard deviation; BP, blood pressure

${ }^{*}$ Comparison of intervention and control arm using chi-square tests for categorical variables and t-tests in independent samples for continuous variables

$\star^{2}$ Comparison of baseline and follow-up data using McNemar tests for categorical variables and paired t-tests for continuous variables)

\section{Discussion}

After five months, this CRT of physician manager education on hypertension management showed no effect of the intervention on BP control rates and changes of ABP. However, outcome-relevant blood pressure improvements were observed in both study arms (12). Intervention practices were more likely to newly implement various hypertension management strategies. In patients with $\mathrm{RH}$, the post-hoc sensitivity analysis showed an effect of the intervention of $-6.75 \mathrm{mmHg}$ in 
TABLE 3

Blood pressure control rates and average ambulatory blood pressure values for the analysis population and patients with and without resistant hypertension, stratified by intervention status

\begin{tabular}{|c|c|c|c|c|c|c|c|c|}
\hline \multirow[b]{2}{*}{ ABP, mmHg } & \multicolumn{2}{|c|}{$\begin{array}{l}\text { Baseline, } \\
\text { mean } \pm \text { SD }\end{array}$} & \multicolumn{2}{|c|}{$\begin{array}{l}5 \text { months follow-up, } \\
\text { mean } \pm \text { SD }\end{array}$} & \multicolumn{2}{|c|}{ Difference } & \multicolumn{2}{|c|}{$p^{* 1}$} \\
\hline & SBP & DBP & SBP & DBP & SBP & DBP & SBP & DBP \\
\hline Study population (N = 103) & $146.7 \pm 12.1$ & $84.7 \pm 9.1$ & $138.5 \pm 13.1$ & $80.6 \pm 10.0$ & $-8.2 \pm 11.8$ & $-4.1 \pm 7.5$ & $<0.001$ & $<0.001$ \\
\hline Intervention $(n=63)$ & $147.2 \pm 11.8$ & $85.1 \pm 8.4$ & $137.9 \pm 13.5$ & $80.9 \pm 10.4$ & $-9.3 \pm 11.9$ & $-4.2 \pm 7.9$ & $<0.001$ & $<0.001$ \\
\hline Control $(n=40)$ & $146.1 \pm 12.7$ & $83.9 \pm 10.2$ & $139.4 \pm 12.7$ & $80.1 \pm 9.5$ & $-6.7 \pm 11.7$ & $-3.8 \pm 6.9$ & 0.001 & 0.001 \\
\hline$p^{* 2}$ & 0.651 & 0.512 & 0.571 & 0.674 & 0.274 & 0.815 & & \\
\hline With resistant hypertension( $N=52)$ & $148.1 \pm 11.3$ & $83.8 \pm 10.7$ & $140.6 \pm 13.6$ & $79.7 \pm 11.0$ & $-7.5 \pm 12.1$ & $-4.1 \pm 7.9$ & $<0.001$ & $<0.001$ \\
\hline Intervention $(\mathrm{n}=28)$ & $148.1 \pm 10.3$ & $85.6 \pm 11.0$ & $137.6 \pm 14.1$ & $79.8 \pm 12.2$ & $-10.5 \pm 11.9$ & $-5.8 \pm 8.7$ & $<0.001$ & 0.002 \\
\hline Control $(n=24)$ & $148.1 \pm 12.7$ & $81.8 \pm 10.2$ & $144.1 \pm 12.5$ & $79.5 \pm 9.6$ & $-4.0 \pm 11.6$ & $-2.3 \pm 6.4$ & 0.105 & 0.093 \\
\hline$p^{* 2}$ & 0.992 & 0.213 & 0.088 & 0.933 & 0.053 & 0.113 & & \\
\hline Without resistant hypertension $(N=51)$ & $145.3 \pm 12.8$ & $85.5 \pm 7.1$ & $136.3 \pm 12.4$ & $81.5 \pm 9.0$ & $-9.0 \pm 11.6$ & $-4.0 \pm 7.2$ & $<0.001$ & $<0.001$ \\
\hline Intervention $(n=35)$ & $146.4 \pm 13.0$ & $48.8 \pm 5.6$ & $138.1 \pm 13.2$ & $81.8 \pm 8.8$ & $-8.3 \pm 11.9$ & $-3.0 \pm 7.1$ & $<0.001$ & 0.018 \\
\hline Control $(n=16)$ & $143.0 \pm 12.3$ & $87.0 \pm 9.6$ & $132.3 \pm 9.5$ & $80.8 \pm 9.5$ & $-10.7 \pm 11.0$ & $-6.2 \pm 7.0$ & 0.002 & 0.003 \\
\hline$p^{* 2}$ & 0.380 & 0.394 & 0.126 & 0.724 & 0.136 & 0.513 & & \\
\hline
\end{tabular}

ABP, ambulatory blood pressure; SD; standard deviation; SBP, systolic blood pressure; DBP, diastolic blood pressure

${ }^{*}$ Comparison of baseline and follow-up data using McNemar tests for categorical variables and paired t-tests for continuous variables:

${ }^{2}$ Comparison of intervention and control data using chi-square tests for categorical variables and t-tests in independent samples for continuous variables

SBP. These results are of high interest with regard to the development and implementation of practice hypertension management strategies. Nevertheless, four aspects need to be discussed in detail.

First, the improvement in both study arms (-8.2 mmHg systolic, $-4.1 \mathrm{mmHg}$ diastolic) suggests a bias due to study participation. Although we used a waiting list control strategy, study participation including the $\mathrm{ABPMs}$ and questionnaires likely influenced the physicians' and patients' awareness of hypertension in both study arms equally, leading to an underestimation of the intervention's effects. This is supported by the fact that BP improved even in patients with longstanding hypertension.

Second, the results of the sensitivity analyses imply that physicians in the intervention group benefited from the education about managing patients with RH. This result is explained by the participatory approach chosen: following the physicians' requests, the CME sessions provided information on diagnostic and therapeutic strategies for RH. However, as our study was not specifically designed for this subgroup, future studies are needed. Given that RH is associated with a 1.34-fold higher risk for all-cause mortality, a 2.11-fold higher risk for nephropathy and a 1.47-fold higher risk for cardiovascular diseases compared to patients without RH (24), our finding suggests that an intervention with input on how to manage $\mathrm{RH}$ bears an enormous public health potential.

Third, the BP changes observed in our study are within the range of those observed in other CRTs
(Figure 1). Like ours, all studies saw improvements in BP within their study populations, but with inconsistent interventional effects $(5,6,9,10,14,15)$.

Fourth, physician managers of the intervention arm did not explicitly request organizational input, yet they newly applied practice strategies between baseline and follow-up. Unlike other CRTs, we focused on rather easy-to-implement internal practice redesign strategies which were selected by choice of the respective physician manager. A longer follow-up period might have shown an impact of these implementations on BP.

\section{Limitations and Strengths}

The primary outcome chosen was difficult to obtain in a patient sample such as ours in the rather short follow-up time, so that a combined outcome (BP control and/or a pre-defined BP reduction) and a longer follow-up (e.g. 12 months) are reasonable for future studies. The drop-out rate of $21 \%$ was within the range described in other CRTs addressing hypertension (11-33\%) (6-10). Cluster drop-outs and patients lacking a follow-up ABPM necessitate larger oversampling to assure study power. In addition, incentives for patients and physicians might help to increase follow-up rates. A major strength of our study is the cluster design which is well known for its proximity to real-life. Using a participatory approach, we tailored the intervention to the physician managers' needs. Finally, the main outcomes were measured by ABPM which is considered the most valid noninvasive BP measurement method. 


\section{Conclusion}

Our educational intervention showed no effect on BP, yet improved the application of practice strategies. Our finding of an interventional effect in the subgroup of patients with $\mathrm{RH}$ warrants further investigation. A larger CRT focusing on these cardiovascular high-risk patients is planned.

\section{Acknowledgments}

We thank Anna Mitchell, MD, Associate Professor, Department for Nephrology, Excellence Center for Hypertension, University Hospital Essen, Deputy Chair of the German Hypertension League; Heike Bruck, MD, Associate Professor, Chief Physician, Clinic for Internal Medicine, Helios Clinic Krefeld; and Ulrich Tholl, MD, Chief Physician, Department for Renal Diseases and Hypertension, St.Antonius-Hospital Kleve, German Hypertension League, for supporting our CME sessions on hypertension management. We are also grateful to Claudia Ose, M.Sc. and Dr. rer. physiol. Ulrike Krahn, Dipl.-Stat., both Center for Clinical Trials Essen (ZKSE) and Institute for Medical Informatics, Biometry and Epidemiology (IMIBE), University Hospital Essen, for their input on statistical issues. Our thanks also go to the participating patients, physicians, and medical assistants for their dedication.

\section{Funding Source}

The study was kindly supported by the Ministry of Innovation, Science and Research, North-Rhine Westphalia, Germany which provided a general grant for teaching and research at the Institute. The source of funding did not influence the study design, analyses, interpretation of results or the decision on publication.

\section{Conflict of interest statement}

The authors declare that no conflict of interest exists.

Manuscript received on 13 August 2015, revised version accepted on 3 November 2015

\section{REFERENCES}

1. Bramlage P, Böhm M, Volpe M, et al.: A global perspective on blood pressure treatment and control in a referred cohort of hypertensive patients. J Clin Hypertens (Greenwich) 2010; 12: 666-77.

2. Labeit AM, Klotsche J, Pieper L, et al.: Changes in the prevalence, treatment and control of hypertension in Germany? A clinicalepidemiological study of 50.000 primary care patients. PloS One 2012; 7 : e52229.

3. Logan AG, Irvine MJ, Mclsaac WJ, et al.: Effect of home blood pressure telemonitoring with self-care support on uncontrolled systolic hypertension in diabetics. Hypertension 2012; 60: 51-7.

4. Heisler M, Hofer TP, Klamerus ML, et al.: Study protocol: The Adherence and Intensification of Medications (AIM) study-a cluster randomized controlled effectiveness study. Trials 2010; 11: 95

5. Heisler M, Hofer TP, Schmittdiel JA, et al.: Improving blood pressure control through a clinical pharmacist outreach program in patients with diabetes mellitus in 2 high-performing health systems: The adherence and intensification of medications cluster randomized, controlled pragmatic trial. Circulation 2012; 125: 2863-72.

6. Hennessy S, Leonard CE, Yang W, et al.: Effectiveness of a two-part educational intervention to improve hypertension control: A cluster-randomized trial. Pharmacotherapy 2006; 26: 1342-7.

7. Lüders S, Schrader J, Schmieder RE, Smolka W, Wegscheider K, Bestehorn K: Improvement of hypertension management by structured physician education and feedback system: cluster randomized trial. Eur J Cardiovasc Prev Rehabil 2010; 17: 271-9.

8. Roumie CL, Elasy TA, Greevy R, et al.: Improving blood pressure control through provider education, provider alerts, and patient education. Ann Intern Med 2006; 145: 165.

9. Carter BL, Bergus GR, Dawson JD, et al.: A cluster randomized trial to evaluate physician/pharmacist collaboration to improve blood pressure control. J Clin Hypertens (Greenwich) 2008; 10: 260-71.
10. Carter BL, Ardery G, Dawson JD, et al.: Physician and pharmacist collaboration to improve blood pressure control. Arch Intern Med 2009; 169: 1996-2002.

11. Hypertension Detection and Follow-Up Program Cooperative Group: Five-year findings of the hypertension detection and follow-up program. I. Reduction in mortality of persons with high blood pressure, including mild hypertension. Hypertension Detection and Follow-up Program Cooperative Group. JAMA 1979; 242: 2562-71.

12. Chobanian AV, Bakris GL, Black HR, et al.: Seventh report of the Joint National Committee on prevention, detection, evaluation, and treatment of high blood pressure. Hypertension 2003; 42: 1206-52.

13. Glynn LG, Murphy AW, Smith SM, Schroeder K, Fahey T: Interventions used to improve control of blood pressure in patients with hypertension. Cochrane Database Syst Rev 2010: CD005182.

14. Pouchain D, Lièvre M, Huas D, et al.: Effects of a multifaceted intervention on cardiovascular risk factors in high-risk hypertensive patients: the ESCAPE trial, a pragmatic cluster randomized trial in general practice. Trials 2013; 14: 318.

15. Reuther LO, Paulsen MS, Andersen M, et al.: Is a targeted intensive intervention effective for improvements in hypertension control? A randomized controlled trial. Fam Pract 2012; 29: 626-32.

16. Campbell MJ, Donner A, Klar N: Developments in cluster randomized trials and statistics in medicine. Stat Med 2007; 26: 2-19.

17. Weltermann B, Viehmann A, Kersting C: Hypertension management in primary care: study protocol for a cluster randomized controlled trial. Trials 2015; 16: 105.

18. Mancia G, Fagard R, Narkiewicz K, et al.: 2013 ESH/ESC guidelines for the management of arterial hypertension: the Task Force for the Management of Arterial Hypertension of the European Society of Hypertension (ESH) and of the European Society of Cardiology (ESC). Eur Heart J 2013; 34: 2159-219.

19. Weltermann B, Schlomann H, Mousa Doost S, Gesenhues S: Hypertension management program improves blood pressure control in primary care. Circulation 2009; 120: 483.

20. Weltermann B, Mousa Doost S, Schlomann H, Gesenhues S: Hypertonie-Management zur Primärprävention: Welche soziobiographischen und medizinischen Faktoren beeinflussen die Qualität der Blutdruckkontrolle? Dtsch Med Wochenschr 2010; 135: 179.

21. Donner A, Klar N: Design and analysis of cluster randomized trials in health research. 1st edition. London: Wiley 2000.

\section{KEY MESSACES}

- This educational intervention was tailored to primary care physicians' information needs in hypertensiology: participants were especially interested in learning how to manage difficult cases.

- Addressing uncontrolled hypertension, this study included patients with long-standing hypertension: on average, hypertension was diagnosed 9 years prior.

- Study participation led to outcome-relevant improvements in both study arms, but there was no greater improvement in the intervention arm.

- The education improved the application of hypertension management strategies in intervention practices.

- A post-hoc sensitivity analysis suggests an interventional effect of -6.75 systolic in patients with resistant hypertension; this finding is in line with the education contents as requested by participating physicians and warrants further investigation.. 
22. Rotondi MA: CRTSize: Sample size estimation functions for cluster randomized trials. R package version 0.4. http://CRAN.R-project.org/ package=CRTSize (last accessed on 29 September 2015).

23. Campbell MJ: Cluster randomized trials in general (family) practice research. Stat Methods Med Res 2000; 9: 81-94.

24. Muntner P, Davis BR, Cushman WC, et al.: Treatment-resistant hypertension and the incidence of cardiovascular disease and end-stage renal disease: results from the Antihypertensive and Lipid-Lowering Treatment to Prevent Heart Attack Trial (ALLHAT) Hypertension 2014; 64: 1012-21.

\section{Corresponding author}

Prof. Dr. med. Birgitta Weltermann, MPH(USA)

Institut für Allgemeinmedizin

Universitätsklinikum Essen

Universität Duisburg-Essen

Hufelandstr. 55

45147 Essen, Germany

birgitta.weltermann@uk-essen.de

(Q) Supplementary material:

eTables, eFigure:

www.aerzteblatt-international.de/16m0167 


\section{Supplementary material to:}

\section{Hypertension Management in Primary Care}

A Cluster Randomized Trial of a Physician-focused Educational Intervention

by Birgitta Weltermann, Christine Kersting, and Anja Viehmann

Dtsch Arztebl Int 2016; 113: 167-74. D0l: 10.3238/arztebl.2016.0167

\begin{tabular}{|c|c|c|c|}
\hline Physicians & $\begin{array}{l}\text { Intervention } \\
\quad(n=12)\end{array}$ & $\begin{array}{l}\text { Control } \\
(n=12)\end{array}$ & $\mathrm{p}^{*}$ \\
\hline Age, years, mean \pm SD & $52.1 \pm 12.3$ & $51.6 \pm 6.7$ & 0.903 \\
\hline Male, $\mathrm{n}(\%)$ & $8(66.7)$ & $9(75.0)$ & 1.000 \\
\hline \multicolumn{4}{|l|}{ Degree, $\mathrm{n}(\%)$ [multiple responses] } \\
\hline Primary care physician (BC), n (\%) & $8(66.7)$ & $6(50.0)$ & 0.408 \\
\hline Internal medicine (BC), $\mathrm{n}(\%)$ & $3(25.0)$ & $4(33.3)$ & 1.000 \\
\hline Internal and general medicine (BC), $\mathrm{n}(\%)$ & $1(8.3)$ & $4(33.3)$ & 0.317 \\
\hline Self-employed, n (\%) & $11(91.7)$ & $12(100.0)$ & 1.000 \\
\hline $\begin{array}{l}\text { Time since medical license, years, } \\
\text { mean } \pm \text { SD }\end{array}$ & $24.6 \pm 8.8$ & $23.5 \pm 7.9$ & 0.770 \\
\hline
\end{tabular}

Percentages are reported for valid cases.

$\mathrm{SD}$, standard deviation; BC, Board Certified

* Data of the intervention and the control arm were compared using chi-square tests for categorical variables

and t-tests in independent samples for continuous variables

\section{eTABLE 2}

Blood pressure control rates and average ambulatory blood pressure values for the study population and patients with and without resistant hypertension, stratified by intervention status

\begin{tabular}{|c|c|c|c|c|}
\hline $\begin{array}{l}\text { ABP } \\
<130 / 80 \mathrm{~mm} \mathrm{Hg}\end{array}$ & Baseline, n (\%) & $\begin{array}{l}5 \text { months } \\
\text { follow-up, } n(\%)\end{array}$ & Difference & $p^{* 1}$ \\
\hline Overall (N = 103) & $0(0.0)$ & $20(19.4)$ & +19.4 & $<0.001$ \\
\hline Intervention $(n=63)$ & $0(0.0)$ & $12(19.0)$ & +19.0 & 0.001 \\
\hline Control $(n=40)$ & $0(0.0)$ & $8(20.0)$ & +20.0 & 0.008 \\
\hline$p^{* 2}$ & & 0.905 & & \\
\hline $\begin{array}{l}\text { With resistant hypertension } \\
(\mathrm{N}=52)\end{array}$ & $0(0.0)$ & $10(19.2)$ & +19.2 & 0.002 \\
\hline Intervention $(n=28)$ & $0(0.0)$ & $6(21.4)$ & +21.4 & 0.031 \\
\hline Control $(n=24)$ & $0(0.0)$ & $4(16.7)$ & +16.7 & 0.125 \\
\hline$p^{* 2}$ & & 0.736 & & \\
\hline $\begin{array}{l}\text { Without resistant hypertensi- } \\
\text { on }(\mathrm{N}=51)\end{array}$ & $0(0.0)$ & $10(19.6)$ & +19.6 & 0.002 \\
\hline Intervention $(n=35)$ & $0(0.0)$ & $6(17.1)$ & +17.1 & 0.031 \\
\hline Control $(n=16)$ & $0(0.0)$ & $4(25.0)$ & +25.0 & 0.046 \\
\hline$p^{* 2}$ & & 0.705 & & \\
\hline
\end{tabular}

\section{ABP, ambulatory blood pressure}

${ }^{*}$ Comparison of baseline and follow-up data using McNemar tests for categorical variables and paired t-tests for continuous variables

${ }^{2}$ Comparison of intervention and control data using chi-square tests for categorical variables and t-tests in independent samples for continuous variables 

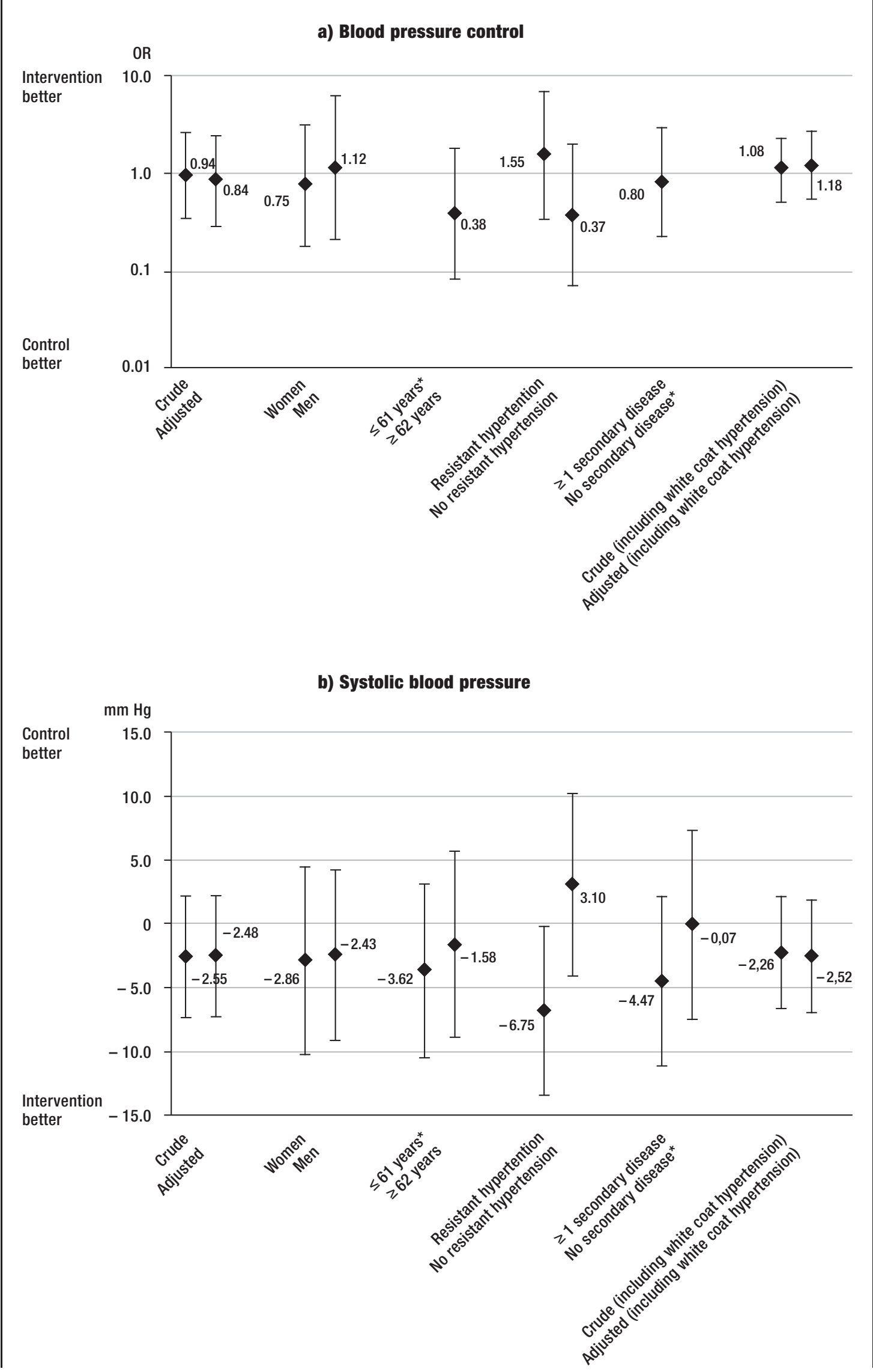
c) Diastolic blood pressure

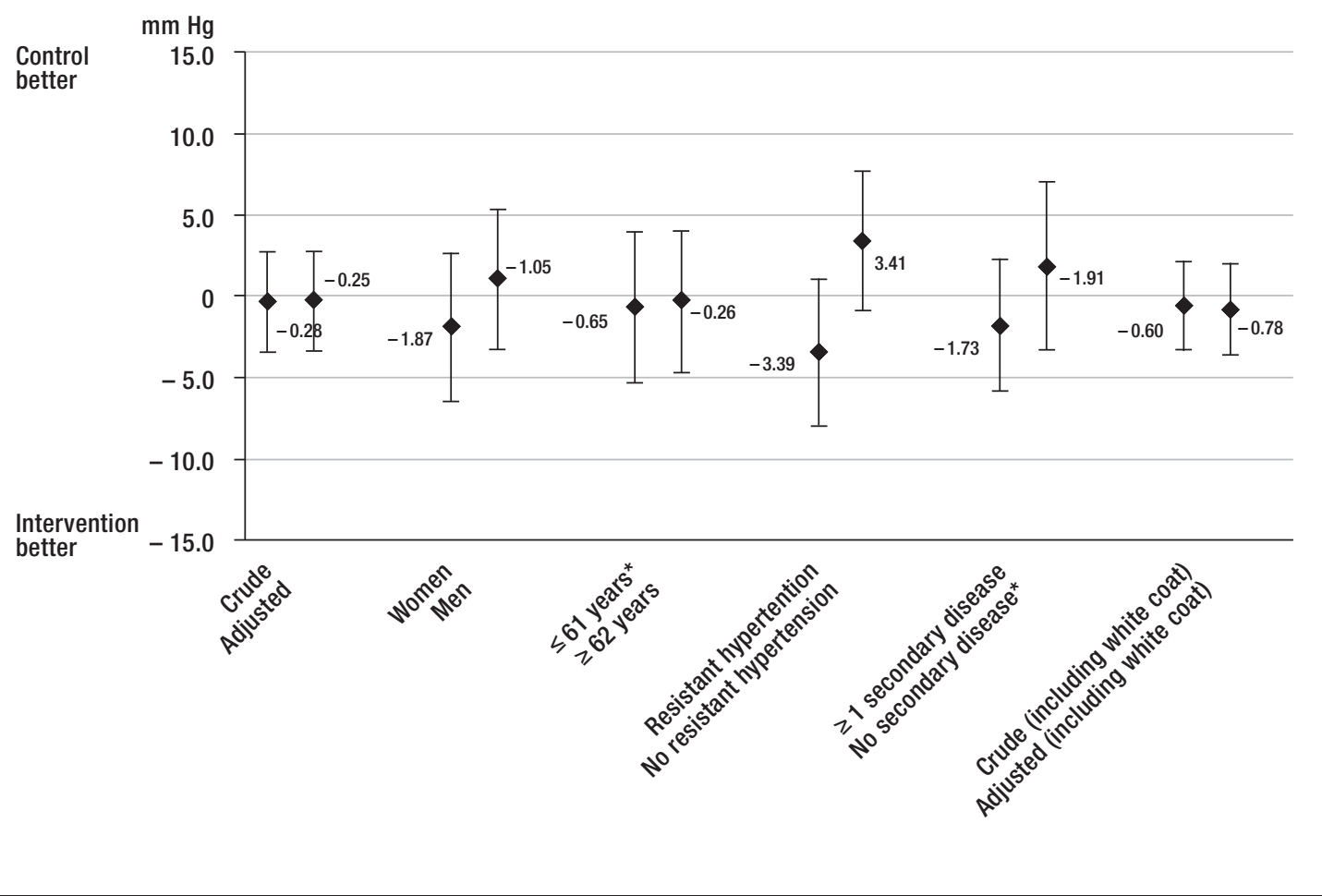

Effects of intervention on blood pressure: crude and adjusted estimates

a) Odds ratios and $95 \%$ confidence intervals for blood pressure control (ambulatory blood pressure $<130 / 80 \mathrm{mmHg}$ ).

b) Changes in systolic blood pressure (in $\mathrm{mmHg}$ ) and $95 \%$ confidence intervals.

c) Changes in diastolic blood pressure (in $\mathrm{mmHg}$ ) and $95 \%$ confidence intervals.

a-c) Crude and adjusted estimates. The models were adjusted for sex, age, and the presence of $\geq 1$ hypertension-related disease and/or diabetes mellitus, unless it was stratified for one of these parameters.

*Model did not converge. 